Original Article

\title{
COVID-19 Pandemic: Influences on the Practice of Neurosurgeons All Over Pakistan
}

\author{
Faisal Feroz Rana', Mazhar Mahmood², Uzma Amin ${ }^{3}$, Rizwan Masood Butt ${ }^{4}$ \\ ${ }^{1}$ Department of Paediatric Neurosurgery, Children Hospital, ${ }^{2}$ Department of Orthopaedic, \\ Allied Hospital, Faisalabad, Pakistan \\ ${ }^{3}$ Department of Dermatology, Lahore General Hospital, ${ }^{4}$ Doctors Hospital, Lahore, Pakistan
}

\section{ABSTRACT}

Objective: The aim of this survey was to observe the impacts of COVID-19 pandemic on neurosurgery practices during this pandemic, assess various types of adaptations taken by them, protective measures during patient examination and effects on their health, family and socioeconomic life.

Material \& Methods: A Questionnaire comprising 32 questions was circulated among practicing Neurosurgeons of Pakistan by social media, e-mails for 8 weeks (January-February 2021) and their responses were analyzed.

Results: 108 participants were involved from all over Pakistan. 32\% respondents stated reduction in clinical practice to a level of less than $25 \%$. While, $10 \%$ reported complete closure of outpatient services during pandemic. There were varied responses on the use of protective measures and most used N95 mask only (31\%). Pandemic also affected the research work, finances and leisure time activities.

Conclusion: Our study showed that neurosurgical practice was influenced by COVID-19 pandemic in many aspects in Pakistan. Proper method of protective measures and COVID testing of patients were lacking among them. Neurosurgeons should follow standard guidelines according to institutional directives in local neurosurgical practices so as to avoid being influenced by such crisis.

Keywords: COVID-19, Pandemic, Practice, Neurosurgeons, Pakistan.

Corresponding Author: Uzma Amin

Department of Dermatology

Lahore General Hospital

Lahore, Pakistan

Email: uzmaamindermatologist@gmail.com

Date of Submission: 06-02-2021

Date of Revision: 07-03-2021

Date of Online Publishing: 31-03-2021

Date of Print: 31-03-2021

DOI: $10.36552 /$ pjns.v25i1.515

\section{INTRODUCTION}

COVID-19 (coronavirus disease-19) is caused by severe acute respiratory response syndrome coronavirus 2 reported to the WHO (world health organization) regional office from Wuhan, China 31st December 2019; the virus has spread to involve almost every country. The novel coronavirus outbreak was declared a global pandemic by the World Health Organization on 
March 11, 2020 which brought the world to a standstill an uneasy calm of fear and Fright engulfed the human race turning the world upside down. ${ }^{1}$

COVID-19 drastically affected every medical practice and had devastating effects on education, religious practices, social norms and economy worldwide. The practice of neurosurgery was an exception, which was being forced into a state of hibernation. There are reports from various parts of the world regarding change in neurosurgical practice during this pandemic. Patients' intensive care has been affected because of more resources being shifted for the care of COVID patients. ${ }^{2}$ Developing countries like Pakistan no doubt suffered a lot as well and this was due to its dense population, limited resources and already constrained health infrastructure. All elective surgeries were stopped in major tertiary care hospitals and patients were afraid to visit hospitals and thus delayed their visits. Entire surgical units had been completely modified to accommodate COVID-19 patients, leading to a reassignment of medical and nursing staff. ${ }^{3}$

To observe the impact of covid-19 on neurosurgery practices, we surveyed practicing neurosurgeons regarding their neurosurgical practice during this pandemic, various adaptations taken by them, use of personal protective equipment during patient examination and multiple effects on the their health, family and socioeconomic life. The purpose of this study was to assess the magnitude of pandemic effects on various dimensions of the neurosurgical practice.

\section{MATERIAL \& METHODS}

\section{Study Design and Setting}

We planned a descriptive survey study to analyze the impact of COVID-19 pandemic on the practice of neurosurgeons all over Pakistan. An online survey among the members of Pakistan Society of neurosurgeons and all other practicing neurosurgeons was done.

\section{Methodology}

A 32-item questionnaire using Google forms was circulated in 6 weeks' duration (Jan-Feb 2021) on various social media groups, email accounts and by direct messaging to various neurosurgeons practicing in different cities of Pakistan.

\section{Inclusion Criteria}

Neurosurgeons with postgraduate qualification/ certification to practice and of any age and any gender were included in the survey.

\section{Exclusion Criteria}

Residents of Neurosurgery post-graduate training were excluded as they were not practicing neurosurgeons.

\section{Data Collection}

The questions were prepared so as to analyze and compare pre-COVID and post-COVID quantum of neurosurgery practice, adaptations made, safety precautions taken, COVID testing regimen and socioeconomic effects during pandemic. Participation in this survey was purely voluntary and respondents filled this questionnaire after giving their consent.

\section{Data Analysis}

The statistical analysis was primarily descriptive. Data was connected on Google spreadsheet and analyzed using python program. Frequency and percentages were calculated for quantitative variables. Stratification among the various variables was also done to see the effects.

\section{RESULTS}

Almost all registered neurosurgeons with the Pakistan Society of neurosurgeons were approached and those unregistered as well. A 
total of108 neurosurgeons participated in this survey. Demographic data of respondents is shown in (Table 1).

\begin{tabular}{|lc|}
\hline Table 1: Demographic of the participants. \\
Variable & Percentage (\%) \\
Gender & \\
Male & 89 \\
Female & 11 \\
Age Range & \\
Less than 40 years & 46 \\
$40-60$ years & 49 \\
More than 60 years & 05 \\
Clinical Experience of Practice & \\
$<5$ years & \\
$5-10$ years & 24 \\
$10-15$ years & 37 \\
$15-20$ years & 25 \\
$>20$ years & 08 \\
& 06 \\
Type of Workplace Affiliation & \\
Government & 37 \\
Private & 14 \\
Multiple & 10 \\
Government \& Private & 32 \\
Semi government & 07 \\
Teaching Workplace & \\
Yes & 79 \\
No & 21 \\
\hline
\end{tabular}

\section{Location of Workplace}

Area wise distribution showed that the majority of neurosurgeons participated form Punjab 61.1\%, while from Kashmir no single participant could enroll. Figure 1 shows the percentages of participants from all four provinces of Pakistan.

\section{Type of Neurosurgical Sub-Specialty}

As far as a subspecialty was concerned major share $(62 \%)$ was of general neurosurgeons, 9\% were pediatric neurosurgeons, $15 \%$ spinal surgeons, $13 \%$ belonged to Trauma \& critical care neurosurgery and $8 \%$ were of neurosurgical oncology. No one form robotic surgery or epilepsy surgery participated in this survey.

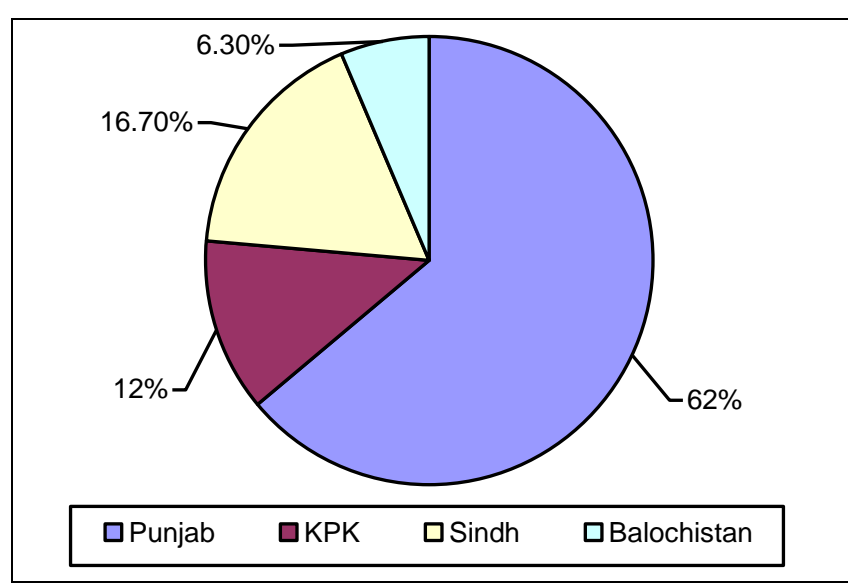

Figure 1: Province wise distribution of participants.

\section{Clinical Experience}

Major share (37\%) of participants of the survey was given by senior neurosurgeons having experience of more than 5 years, while those with experience of $10-15$ years were also higher in percentage i.e. $25 \%$. Thus, our study involved the active participation of neurosurgeons with more practical experience.

\section{Role as Warrior}

$68 \%$ of the respondents believed that that their role was useful and important in the battle against COVID-19 while 9\% didn't feel their importance in this regard, whereas $20 \%$ were even doubtful to be playing any beneficial role in combating this pandemic.

\section{Influence on Clinical Services}

$86 \%$ participants stated that there was a decrease in the number of patients visiting OPD (outpatient department), $14 \%$ did not feel any reduction and $5 \%$ were not sure about that. $10 \%$ declared that no OPD services were given by their department during pandemic, while $23 \%$ said that it was reduced to telemedicine only. Reduction in OPD was observed to a level of less than $25 \%$ stated by $32 \%$ participants. According to $63 \%$ of respondents, services in OPD were continued 
during pandemic. Table2 shows the reduction in

Table 2: Relationship of area of workplace with a reduction in the number of patients visiting the outpatient department.

$\begin{array}{lc}\text { Location of } & \begin{array}{c}\text { \% or Respondents Stating } \\ \text { Workplace } \\ \text { Reduction during Pandemic }\end{array} \\ \text { Punjab } & 54 \% \\ \text { KPK } & 10 \% \\ \text { Sindh } & 12 \% \\ \text { Baluchistan } & 5 \% \\ \text { Total } & 81 \%\end{array}$

\% Stating No Reduction during Pandemic

$\begin{array}{rr}8 \% & 1 \% \\ 2 \% & 1 \% \\ 3 \% & 2 \% \\ 1 \% & 1 \% \\ 14 \% & 5 \%\end{array}$

Table 3: Relationship of Age of participants with the use of protective measures.

\begin{tabular}{lccccccc|} 
Age Range & $\begin{array}{c}\text { Surgical } \\
\text { Mask }\end{array}$ & N 95 Mask & $\begin{array}{c}\text { Protective Measures (\% of Respondents) } \\
\text { Double } \\
\text { Mask }\end{array}$ & $\begin{array}{c}\text { Mask with Face } \\
\text { Shield \& Goggles }\end{array}$ & $\begin{array}{c}\text { Mask with Face } \\
\text { Shield Gown }\end{array}$ & PPE & No PPE \\
$<$ <0 years & 10 & 20 & 8 & 2 & 3 & 0 & 5 \\
40 - 60 years & 9 & 1 & 6 & 3 & 3 & 4 & 1 \\
$>$ 60 years & 5 & 4 & 5 & 2 & 3 & 1 & 0 \\
Total & 24 & 31 & 19 & 7 & 8 & 5 & 6 \\
\hline
\end{tabular}

the number of outdoor patients according to provinces of Pakistan and it shows maximum reduction in the province of Punjab and then in Sindh. There was a drop of $25-50 \%$ in emergency services observed by $56 \%$ of respondents. Elective cases were stopped for almost two months by $42 \%$ of respondents.

\section{Influence on Patients' Examination}

As far as examination of patients in OPD and emergency was concerned, $52 \%$ respondents admitted that they avoided detailed close examination with fear of virus transmission and relied on history only; while $13 \%$ didn't have such fear.

\section{Use of Protective Measures}

Regarding observing Standard Operating Procedures (SOP) during OPD, 19\% relied on wearing double masks only, 31\% chose N95 mask only, while whole PPE (personal protective equipment) was worn by only $6 \%$ respondents. The effect of age on the use of protective measures was stratified and is shown in Table 3 and it showed that PPE was mostly worn by doctors in the age range of $40-60$ years.

Figure 2 shows the availability of various types of protective equipment to respondents at their workplace and it shows that complete PPE kits were available to only $44 \%$ of doctors and $12 \%$ had no freely available equipment even the surgical masks.

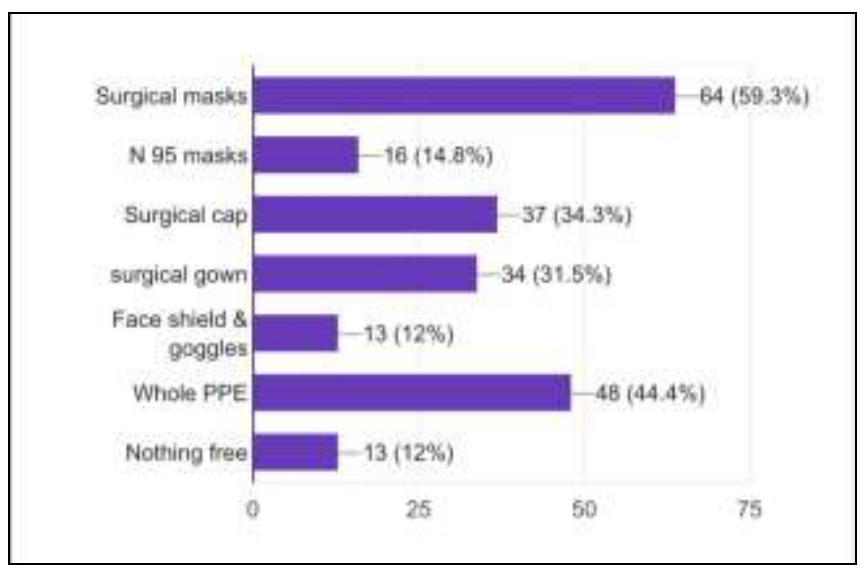

Figure 2: Availability of protective equipment at work place. 


\section{Influence on Patient Selection and COVID Testing}

Opinion about COVID testing varied markedly among our respondents. 38\% stated to test for COVID only in those cases that have been planned for surgery, $28 \%$ thought to test only those who are symptomatic, while $14 \%$ suggested to test all who get admitted in the ward. The rest thought to test patients those at risk only.

Only 35\% participants realized that they have changed their criteria for selection of patients for elective surgery. And only $18 \%$ participants admitted to avoid some procedures during a pandemic like drilling for bones from fear of aerosolization. Regarding COVID testing before emergency procedure, $85 \%$ neurosurgeons didn't require a COVID negative report. Before elective procedures, 55\% required COVID negative report, $23 \%$ screened by symptomatology while $22 \%$ didn't bother for any report.

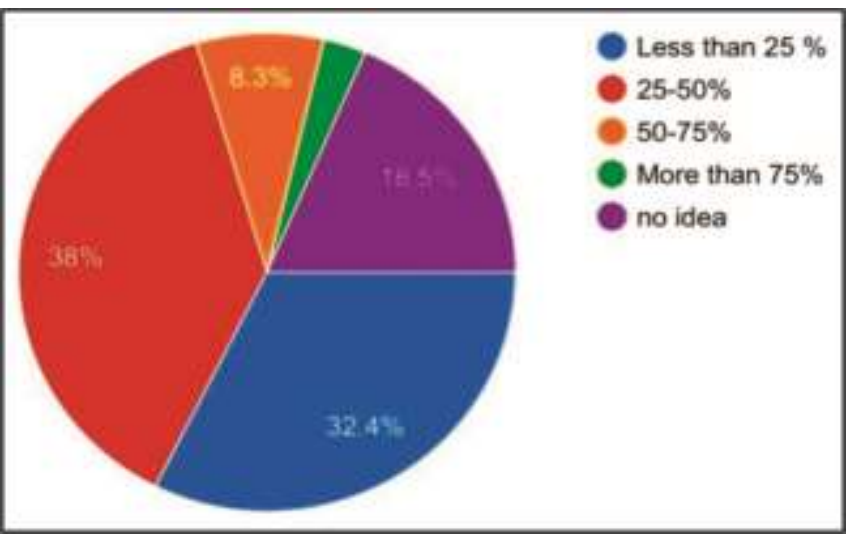

Figure 3: Financial hold back suffered by participants during pandemic.

\section{Influence on Financial Status}

Financial burden born by neurosurgeons due to decrease in their private practice was also questioned and is shown in Figure3in the form of a percentage.

\section{Influence of Change in Practice on Personal Life}

Finally, during lockdown and off duty hours, how our neurosurgeons utilized their free time was also inquired and was presented in (Figure 4) which showed the increased trend of using online learning modalities. $78 \%$ neurosurgeons preferred to devote quality time at home to their family.

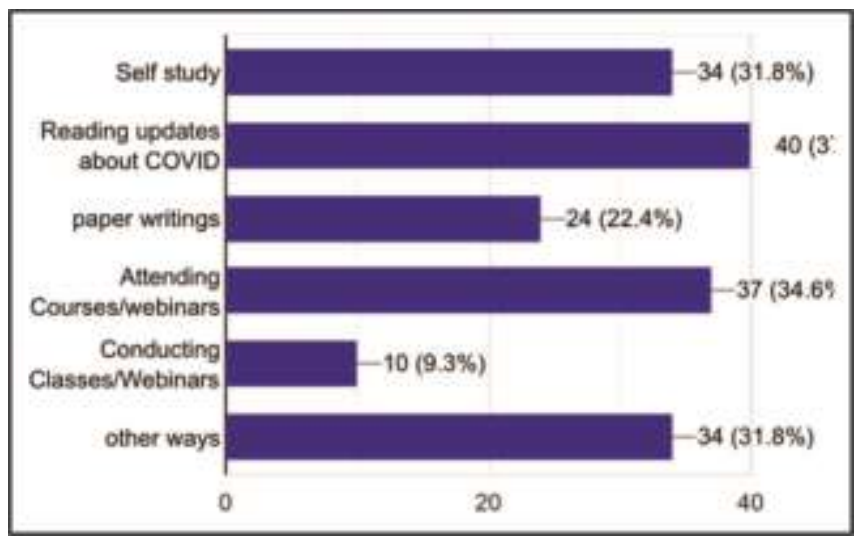

Figure 4: Time utilization preferences during off-duty in pandemic.

We analyzed the effect of location of workplace at various responses and variables related to the practice of neurosurgeons in outdoor and indoor department of their workplace. Table 4 summarizes the comparison of responses withthe location of the workplace according to provinces of Pakistan.

\section{DISCUSSION}

Corona virus disease-19 also known as the severe acute respiratory syndrome has spread to involve the five continents and more than 200 countries. Pakistan being a COVID hotspot expected alteration in the dynamics of health practices been witnessed in every specialty; neurosurgery being no exception. At the time of writing of this article, there have been a total of 102 million COVID cases worldwide with a higher prevalence 
in America, Brazil, and Ireland. Among countries of Asia, the highest number of new cases has been recorded in India. Pakistan is also suffering from the second wave of the pandemic affecting an average of 1500 new diagnosed cases per day for the last 2 months with a total number of 553,123 cases. $^{4}$ This increased number of cases may be due to the relaxation of lockdown and high population density. As the virus affects primarily the respiratory system the neurological manifestations are well recognized thus presenting to the neurosurgeons. Neurosurgical practice and training are not isolated from this epidemic situation because according to American guidelines elective cases can be postponed during a pandemic due to fewer resources available and all neurosurgical societies worldwide have changed their existing protocols for care of patients and elective procedures. ${ }^{5}$ Therefore, we intended to study the effects of these resources on the neurosurgical services, resident training, and socioeconomic impact on the neurosurgeon.

Out of total of 600 potential recipients, we received only 116 responses. Among 116, five were excluded as they belonged to other countries and 3 didn't give their consent for giving their data; thus our study comprised responses from 108 neurosurgeons from all over Pakistan showing male predominance (89\%). These results are comparable to those by Tejas et al $^{6}$ who observed only 4 female neurosurgeons and 196 males. Whereas our study comprised 11 female variables.
Table 4: Stratification of responses from all provinces with

\section{Demographic Variables Punjab Sindh KPK Baluchistan Total

$\begin{array}{llllll}(\mathbf{N}=108) & (\%) & (\%) & (\%) & (\%) & (\%)\end{array}$

1. Did your department continued outpatient services during pandemic?

$\begin{array}{llllll}\text { Yes } & 39 & 16 & 22 & 13 & 90 \\ \text { No } & 04 & 03 & 02 & 01 & 10\end{array}$

2. Have your department been upgraded regarding COVID protective measures?

$\begin{array}{llllll}\text { Yes } & 41 & 14 & 08 & 04 & 67 \\ \text { No } & 12 & 10 & 04 & 02 & 28 \\ \text { No idea } & 02 & 02 & 00 & 01 & 05\end{array}$

3. With fear of being infected, do you avoid detailed examination of patient in OPD and rely on history only?

$\begin{array}{llllll}\text { Yes } & 36 & 12 & 20 & 18 & 86 \\ \text { No } & 06 & 03 & 03 & 02 & 14\end{array}$

4. Do you have protective equipment freely available at your workplace?

$\begin{array}{llllll}\text { Yes } & 36 & 12 & 21 & 19 & 88 \\ \text { No } & 04 & 02 & 04 & 02 & 12\end{array}$

5. Do you avoid doing certain surgical procedures during pandemic?

$\begin{array}{llllll}\text { Yes } & 10 & 07 & 08 & 08 & 33 \\ \text { No } & 41 & 14 & 08 & 04 & 67\end{array}$

6. Do you avoid procedures having risk of aerosol formation?

$\begin{array}{llllll}\text { Yes } & 09 & 08 & 03 & 10 & 30 \\ \text { No } & 56 & 19 & 07 & 00 & 70\end{array}$

7. Is there any reduction in number of patients visiting in your outpatient department?

$\begin{array}{llllll}\text { Yes } & 54 & 12 & 10 & 05 & 81\end{array}$

$\begin{array}{llllll}\text { No } & 08 & 03 & 02 & 01 & 14\end{array}$

$\begin{array}{llllll}\text { Not sure } & 01 & 02 & 01 & 01 & 05\end{array}$

8. Would you operate a COVID +ve patient for elective surgery?

$\begin{array}{llllll}\text { Yes } & 08 & 07 & 09 & 07 & 31 \\ \text { No } & 31 & 14 & 12 & 12 & 69\end{array}$

9. Has your own research work been affected by pandemic?

$\begin{array}{llllll}\text { Yes } & 21 & 13 & 06 & 01 & 43\end{array}$

$\begin{array}{llllll}\text { No } & 07 & 08 & 10 & 09 & 33\end{array}$

$\begin{array}{llllll}\text { Not sure } & 06 & 05 & 03 & 02 & 17\end{array}$

$\begin{array}{llllll}\text { Not applicable } & 03 & 00 & 01 & 03 & 07\end{array}$

10. Has pandemic affected training of your residents?

$\begin{array}{llllll}\text { Yes } & 41 & 12 & 06 & 06 & 65\end{array}$

$\begin{array}{llllll}\text { No } & 01 & 00 & 00 & 00 & 01\end{array}$

$\begin{array}{llllll}\text { Not sure } & 03 & 04 & 00 & 02 & 09\end{array}$

$\begin{array}{llllll}\text { Not applicable } & 07 & 07 & 06 & 05 & 25\end{array}$

participants and 89 males. The median age of our participants was 43 years.

Among all participants, 37\% had more than 5 years' experience, and one-quarter participants had more than 10 years of practice. As this is obvious that the seniors would have been having 
an excellent practice before the pandemic and their data in this survey will be a true picture of the influence of COVID on the neurosurgical practice. These findings are consistent with those of Deora et al who observed the median age to be 39 years in his survey among 176 neurosurgeons of India and their median work

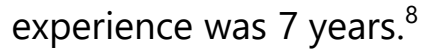

Reduction in the number visiting the outpatient department was most noticed by respondents belonging to the province of Punjab where $54 \%$ respondents out of a total $62 \%$ stated pandemic effect on OPD. In our study, $83 \%$ of neurosurgeons stated a drop of $20-50 \%$ in OPD services thus OPD consultation suffered a major reduction. This may be due to fear of contracting the disease among patients planning to visit OPD, 'stay at home' regulations by government to avoid crowding of people and to utilize resources for COVID patients; as a result, such practices showed to be beneficial for health care providers as the percentage of neurosurgeons being affected themselves by COVID was observed to be $4.8 \%$ in our survey. Jean et $\mathrm{al}^{7}$ in a survey in 60 countries found a drop of $52 \%$ in OPD clinics and elective cases which is higher than observed in our country.

OPD services through telemedicine were done by only $23 \%$ setups which need to be improved but is comparable to that in our neighbor country India where tele-OPD was served by $20 \%$ neurosurgeons and OPD was closed by $17.6 \%{ }^{8}$ However, in our study we observed complete closure of OPD during pandemic by $10 \%$ neurosurgeons. This may be due to the fact that $78 \%$ participants belonged to teaching setup and might have to train residents giving the benefit of services delivered by them enabling them to run OPD, or might be related to patient burden as well because $10 \%$ of neurosurgeons stated that there was no reduction in the number of patients visiting $O D$ during pandemic. Thus this fact stresses the need for the availability of more qualified neurosurgeons in tertiary care setups where patient influx is more than the availability of health workers. In spite of such workload, $10 \%$ of our respondents felt that they have no role to play in the battle against this pandemic.

We observed a wide disparity among respondents regarding the patient's selection for elective surgery and COVID testing prior to the procedure. $50 \%$ of our respondents admitted that there was no change in their criteria for triage and selection of cases for elective operation and only $35 \%$ were followed triage and recommendations for preoperative testing. These results vary from those found by Ranjith et $\mathrm{al}^{9}$ who observed $84 \%$ of neurosurgeons following triage guidelines and performing only emergency cases.

Only $53 \%$ bothered for COVID negative report before elective and for emergency cases, $85 \%$ of our participants didn't demand COVID testing. These observations show that our neurosurgeons had not adapted to the changed protocols as had done by other countries like China, Italy and US (united states). ${ }^{10}$ Our results regarding preoperative COVID testing also differ from India as well where neurosurgeons have adapted to triage the patients according to elective or emergency care even if there is an emergency indication of surgery. ${ }^{11}$

While adapting and following SOPs for protection against COVID transmission, neurosurgeons in our survey preferred to use only N95 mask as part of personal protection and $62 \%$ admitted to feel uncomfortable in doing duty with PPE which was used by only $6 \%$ of respondents during the examination of patients. To see the effect of age on following protective measures, stratification was done, which showed that age group of fewer than 40 years was more peculiar in following SOP \& had maximum use of various masks, face shields Gowns, and PPE during patients examination than those in other age groups. This showed that our young neurosurgeons have keenly adapted to new norms than their elder colleagues.

We found $67 \%$ response regarding the 
upgrading of workplace for safety measures and PPE was declared to be available to $47 \%$ participants. We also observed that $52 \%$ relied on history only and avoided detailed physical examination of patients in OPD to avoid virus transmission. These observations are in accordance with the results of a study by Deora $\mathrm{H}$ et $\mathrm{al}_{1}{ }^{8}$ but these don't match with the recommended safety guidelines about the use of PPE. ${ }^{11}$

As far as personal influence is concerned, a financial burden of $25-50 \%$ was experienced by $38 \%$ of participants and only $8 \%$ had to bear $60 \%$ financial constraints but this data did not vary among those working in public versus private setups. Research work for those working in public setup was greatly affected due to reduction in patient influx and it was experienced by $43 \%$ of participants. Similar results were observed by Tejas $\vee$ et al. ${ }^{6}$

\section{Recommendations}

Effects and influences of this pandemic will be observed in years to come. We require nationwide collaborative efforts to reduce impacts on medical, educational mental, and social lives and to adapt to this new norm era. Practices should be continued to avoid patients' worsening in a wait for surgery but with all protective measures and universal COVID testing regimens.

Telemedicine, virtual online consultations and webinar-based meetings should be developed throughout the country as routine practices to help needy patients.

\section{Limitations}

Residents although contribute to the main bulk of patient care in teaching setup, but were not actively invited because the study was intended to include the neurosurgical practice of all types i.e., public sector and private, etc.

It was not an epidemiological study to observe prevalence or incidence of neurosurgical cases being affected by pandemic thus included less number of respondents than actually may be required and practicing, therefore, we relied on less few participants.

\section{CONCLUSION}

We concluded from our study that the neurosurgical practice was influenced by the COVID-19 pandemic in many aspects in Pakistan. Neurosurgeons should follow algorithms for scheduling neurosurgery cases and patient coverage; and implement protocols according to institutional directives in local neurosurgical practices so as to avoid being influenced by such pandemic situations.

\section{REFERENCES}

1. Cucinotta D, Vanelli M. WHO declares COVID -19 A pandemic. Acta Biomed. 2020; 91: 157-160.

2. Gupta $P$, Muthukumar N, Rajshekhar $V$, et al. Neurosurgery and neurology practices during the novel COVID-19 pandemic: a consensus statement from India. Neurol India, 2020; 68: 246-254.

3. Jafri LA, Javed M, Sajjad A, et al. Neurological care and training in the times of covid-19: a tertiary care center experience. Pak J Neurol Sci. 2020; 15 (3): 4-10.

4. World Health Organization. Corona Virus disease (COVID-19) outbreak situation, 2021.

5. Germano A, Raffa G, Angilero FF, et al. Coronavirus disease 2019 (COVID-19) and neurosurgery: literature and neurosurgical societies' recommendations update. World Neurosurg. 2020; 139: e 812-e817.

6. Tejas V, Goyal N, Dash C; et al. Impact of COVID-19 pandemic on Neurosurgical practice in India: results of an anonymized national survey. Neurology India, 2020; 68 (3): 595.

7. Jean WC, Ironside NT, Sack KD, et al. The impact of COVID-19 on neurosurgeons and the safety for triaging non-emergent operations: a global neurosurgery study. Acta Neurosurgir. 2020; 162 (2): 1229-1240. 
8. Deora $\mathrm{H}$, Mishra $\mathrm{S}$, Tripathi $\mathrm{M}$, et al. Adapting neurosurgery practice during the COVID-19 pandemic in the Indian subcontinent. World Neurosurg. 2020; 42: e396-e406.

9. Ranjith RK, Rajshekhar V. Impact of COVID-19 pandemic on neurosurgical practice in India: A survey on personal protective equipment usage, testing and perceptions on disease transmission. Neurol India, 2020; 68 (5): 1133-1138.

10. Germano A, Raffa G, Angileri FF, et al. Corona virus disease 2019 and neurosurgery: Literature and neurosurgical society's recommendations update.
World Neurosurg. 2020; 139: e812-e817.

11. Ansari A, Kato $Y$, Tang J. Letter to the editor: Neurosurgical practice in COVID-19 pandemic: from the point of view of academic departments in India, Japan and China. Br J Neurosurg. 2020; 34: 355-356.

12. Muhammad S, Tanikawa R, Lawton MT, et al. Letter: safety instructions for neurosurgeons during COVID-19 pandemic based on recent knowledge and experience. Neurosurgery, 2020; 87 (2): E 220-E221.

"We fell asleep in one world and woke up in another

Suddenly Disney is out of magic

Paris is no longer romantic

New York doesn't stand up anymore

The Chinese wall is no longer a fortress

And MECCA is empty"

(Haroon Rashid)

\section{Additional Information}

Disclosures: Authors report no conflict of interest.

Human Subjects: Consent was obtained by all patients/participants in this study.

\section{Conflicts of Interest:}

In compliance with the ICMJE uniform disclosure form, all authors declare the following:

Financial Relationships: All authors have declared that they have no financial relationships at present or within the previous three years with any organizations that might have an interest in the submitted work.

Other Relationships: All authors have declared that there are no other relationships or activities that could appear to have influenced the submitted work.

Ethical review board approval

This was an online digital questionnaire based study and didn't involve single institution. Authors declare that individual consent was taken from each respondent before they filled the survey form.

\section{Authors Contributions}

\begin{tabular}{|l|l|l|}
\hline Sr.\# & Author's Full Name & Intellectual Contribution to Paper in Terms of: \\
\hline 1. & Faisal Feroz Rana & $\begin{array}{l}\text { Study design, methodology, data collection, calculations, results analysis and } \\
\text { data interpretation }\end{array}$ \\
\hline 2. & Mazhar Mahmood & Analysis of data, results interpretation and literature review \\
\hline 3. & Uzma Amin & Paper writing, referencing and manuscript writing. \\
\hline 4. & Rizwan Masood Butt & Analysis of data and interpretation of results etc. \\
\hline
\end{tabular}

